\title{
An Effect of Extrarenal Beta Adrenergic Stimulation on the Release of Renin
}

\author{
Ian A. Reid, Robert W. Schrier, and Laurence E. Earley \\ From the Departments of Medicine and Physiology and the Cardiovascular \\ Research Institute, University of California San Francisco, \\ San Francisco, California 94122
}

\begin{abstract}
A B S T R A C T The present study was undertaken to examine whether the beta adrenergic agonist, isoproterenol, increases plasma renin activity (PRA) by activation of intrarenal or extrarenal pathways. The effects of intravenous (i.v.) and renal arterial infusion of isoproterenol on PRA and renin secretion rate (RSR) were compared in anesthetized dogs. In 12 studies in 9 dogs i.v. infusion of isoproterenol (0.009$0.018 \mu \mathrm{g} / \mathrm{kg}$ per $\mathrm{min}$ ) was associated with an increase in PRA from 14.7 to $35.7 \mathrm{ng} / \mathrm{ml}$ per $3 \mathrm{hr}(P<0.001)$. PRA decreased to $19.4 \mathrm{ng} / \mathrm{ml}$ per $3 \mathrm{hr}(P<0.001)$ after cessation of the infusion. In innervated kidneys RSR increased from 1640 to $5062 \mathrm{U} / \mathrm{min}(P<0.02)$ and decreased to $2132 \mathrm{U} / \mathrm{min}$ after cessation of the infusion $(P<0.05)$. In denervated kidneys the control RSR was significantly lower $(455 \mathrm{U} / \mathrm{min})$ but still increased during i.v. infusion of isoproterenol to 2762 $\mathrm{U} / \mathrm{min}(P<0.001)$ and decreased to $935 \mathrm{U} / \mathrm{min}(P$ $<0.001)$ after the infusion was stopped. These changes in PRA and RSR were associated with an increase in cardiac output averaging $49 \%$ and a large decrease in total peripheral resistance. These effects of i.v. isoproterenol to increase RSR were not mediated by changes in renal perfusion pressure since this was held constant by adjusting a suprarenal aortic clamp. In addition, there were no changes in glomerular filtration rate, renal plasma flow, or electrolyte excretion in either denervated or innervated kidneys during i.v. infusion of isoproterenol, and the concentration of potassium in
\end{abstract}

Preliminary reports of this work have been presented at a Workshop on the Control of Renin Secretion, Santa Ynez, Calif., 26 August 1971, and at the American Society of Nephrology, Washington, D. C., 22 November 1971.

Dr. Reid is a Bay Area Heart Research Committee Fellow and Dr. Schrier is an Established Investigator of the American Heart Association.

Received for publication 28 December 1971 and in revised form 14 February 1972. plasma was unchanged. Prior hypophysectomy abolished the antidiuretic effect of i.v. isoproterenol but did not prevent the effect on RSR. In contrast, renal arterial infusion of isoproterenol at the same dose had no apparent effect on PRA and RSR in seven studies in five dogs and also did not produce changes in cardiac output, peripheral resistance or renal hemodynamics. These results do not provide evidence for a role of intrarenal beta adrenergic receptors in the control of renin release and indicate that the effect of beta adrenergic stimulation with isoproterenol to increase the release of renin is mediated by an extrarenal mechanism. Since the effect of i.v. isoproterenol occurred in the absence of changes in plasma potassium concentration, renal perfusion pressure, glomerular filtration rate, renal plasma flow, and electrolyte excretion and was not abolished by renal denervation, the possibility must be considered that the effect on renin secretion is mediated by circulatory factors. The changes in systemic hemodynamics which occurred with i.v. but not renal arterial infusion of isoproterenol may be involved in the initiation of such a pathway.

\section{INTRODUCTION}

There is now considerable evidence that the sympathetic nervous system plays a role in the regulation of renin secretion. Several maneuvers which stimulate sympathetic neural pathways, including hemorrhage $(1-4)$, carotid occlusion (2), direct electrical stimulation of renal nerves (5-7), infusion of catecholamines or ganglionic stimulating agents $(2,5,8-10)$, hypoglycemia $(10,11)$, and stimulation of the midbrain (1214) have been shown to increase the release of renin. The mechanisms by which sympathetic nervous stimulation increases renin release are unclear. With some maneuvers, such as severe hemorrhage, decreases in 
arterial pressure may be responsible, at least partially, for the increased release of renin $(1,4)$. In some of these circumstances, however, the systemic arterial pressure may either increase (carotid occlusion [2], direct renal nerve [7] and midbrain stimulation [13, 14]) or remain unchanged (moderate hemorrhage [2] and hypoglycemia $[10,11])$. Nevertheless, even in the presence of an increased or unchanged arterial pressure sympathetic neural stimulation could cause renal vasoconstriction and diminish pressure at the level of some intrarenal pressure-sensitive receptors that influence the release of renin from cells of the juxtaglomerular apparatus $(3,15,16)$. Evidence that such could be the case is the finding that, when measured, renal blood flow, glomerular filtration rate, or both may diminish during maneuvers that increase sympathetic discharge $(2-5,8,9)$. An additional or alternative pathway whereby the sympathetic nervous system could stimulate the release of renin may relate to an associated diminution in the rate of sodium delivery to (17), or transport at (18), the macula densa. In addition to the possible importance of the baroreceptor and macula densa mechanisms as mediators of renin release secondary to sympathetic discharge, some investigators $(6,7,19-21)$ have suggested that stimulation of the renal nerves may increase renin release by a direct effect on cells of the juxtaglomerular apparatus. This possibility has been considered tenable since juxtaglomerular cells of the afferent arteriole are richly innervated by sympathetic nerves $(22,23)$. Moreover, it has been reported recently that stimulation of renal nerves increases the release of renin in normal (19) and nonfiltering (20) kidneys in which vascular reactivity has been diminished by infusing papaverine. The responsiveness of any pressure-sensitive receptor (baroreceptor mechanism) may be abolished by the renal arterial infusion of papaverine $(19,20)$ and any effect on renin release related to delivery of filtrate to the macula densa is presumably precluded in the nonfiltering kidney (20). On the basis of these resulis $(19,20)$ it has been suggested that sympathetic stimulation increases the renal release of renin by a direct neural action on cells of the juxtaglomerular apparatus. In support of this view are observations that catecholamines may increase the production or release of renin by renal cortical slices in vitro (24).

It has been proposed that intrarenal beta adrenergic receptors may be involved in such a direct effect of the sympathetic nervous system to increase the release of renin (21). Although the i.v. infusion of isoproterenol increases plasma renin (25), a role of an associated decrease in arterial pressure has not been eliminated. Some studies have suggested that isoproterenol stimulates release of renin through intrarenal path- ways, but the design of such studies permits alternative conclusions $(8,25,26)$. The beta adrenergic blocking agent, propranolol, has been reported to abolish or attenuate the effect of hypoglycemia (11), midbrain stimulation (14), renal nerve stimulation (6), and catecholamine infusion $(8,11)$ to increase the release of renin. However, these studies have not distinguished between stimulation of extrarenal and intrarenal beta adrenergic receptors in the control of renin release.

The present investigation was undertaken to test more directly for the presence of intrarenal beta adrenergic receptors involved in the control of renin release. Experiments were designed to compare the effect on renin secretion of i.v. and renal arterial infusions of the beta adrenergic agonist isoproterenol. The range of intrarenal doses of isoproterenol used was such that no evidence of systemic effects of beta adrenergic stimulation was present yet the renal arterial concentration of the drug was equal to or in excess of that achieved during the i.v. infusion. An increase in renin secretion was observed only during the i.v. infusion of isoproterenol. Therefore, these results do not provide evidence for an intrarenal beta adrenergic receptor controlling renin release but do support the view that extrarenal beta adrenergic receptors can influence the release of renin. This effect of extrarenal beta adrenergic stimulation to increase the release of renin was not related to measured changes in any of the variables known to influence the release of renin.

\section{METHODS}

Experiments were performed in 14 mongrel dogs of either sex weighing $20-30 \mathrm{~kg}$. In these animals food was withheld $18 \mathrm{hr}$ before study, but water was allowed ad lib. On the day of study the animals were anesthetized with i.v. pentobarbital $(30 \mathrm{mg} / \mathrm{kg})$, intubated, and ventilated with a Harvard respirator (Harvard Apparatus Co., Inc., Millis, Mass.). Light anesthesia was maintained throughout the experiment by the intermittent administration of pentobarbital. All animals received $5 \mathrm{mg}$ of deoxycorticosterone acetate i.m. A solution of $2.5 \%$ glucose and water was infused i.v. at $20 \mathrm{ml} / \mathrm{min}$ for $50-75 \mathrm{~min}$ during which time surgical procedures were performed. In six dogs hypophysectomy was performed through the buccal approach on the morning of the experiment. In all animals polyethylene catheters were placed in both ureters and renal veins through bilateral flank incisions. 15 kidneys in 10 animals were denervated by stripping and severing the renal nerves and then applying $95 \%$ alcohol to the renal pedicle. In five animals a 23-gauge needle was placed in one renal artery. The patency of the needle was maintained by the infusion of $2.5 \%$ glucose at a rate of $0.5 \mathrm{ml} / \mathrm{min}$. In eight animals a Blalock clamp was placed around the aorta above the origin of both renal arteries. In all animals catheters were inserted into the aorta and inferior vena cava via the femoral artery and vein, respectively, for continuous measurement of arterial and venous pressure with Statham transducers (Statham Instruments, Inc., Oxnard, Calif.) and a direct writing Gilson recorder (Gilson Medical Electronics, Inc., Middleton, 
Wis.). In the animals with the Blalock clamp around the aorta the arterial pressure also was measured above the clamp via a catheter in the brachial artery. In all but one animal a catheter was inserted into the right atrium via a jugular vein through which indocyanine green was injected for determining cardiac output by a dye dilution method using a Gilson densitometer and the Lexington Instruments Cardiac Output Computer (Lexington Instruments Corp., Waltham, Mass.). Arterial blood for determining dye dilution was withdrawn from the brachial artery by a Lexington Instruments pump. After completion of the surgery, an intravenous infusion of $2.5 \%$ glucose $(0.5 \mathrm{ml} /$ min) was started with sufficient inulin and $p$-aminohippuric acid $(\mathrm{PAH})^{1}$ to maintain blood levels of these substances between 15 and 25 and 1 and $3 \mathrm{mg} / 100 \mathrm{ml}$, respectively. After 1-1 $1 \frac{1}{2}$ liters of $2.5 \%$ glucose had been infused, the rate was decreased to $4 \mathrm{ml} / \mathrm{min}$ above urine flow. The experiment was started after stabilization of urine flow. Urine was collected at 5 - or 10 -min intervals throughout the experiment, and arterial and renal venous blood samples were collected at the midpoint of alternate collections of urine. Cardiac output measurements were made every third period of the experiment. Twelve studies with i.v. infusion of isoproterenol were performed in nine animals, 5 of which were hypophysectomized. In 10 of these experiments the renal perfusion pressure was lowered by $9-33 \mathrm{~mm} \mathrm{Hg} \mathrm{1-1 \frac {1 } { 2 } \mathrm { hr }}$ before starting the experiment and then maintained at the same level throughout the experiment. In the other two experiments (dogs 1 and 9) the renal perfusion pressure was not lowered before the experiment but did remain constant throughout the study. Seven studies with renal arterial infusion of isoproterenol were performed in five animals. Since arterial pressure did not change during the renal arterial infusion of isoproterenol, an aortic clamp was not used in these experiments. Except for the route of administration of isoproterenol the following protocol was used for all of the studies. After three to five control periods isoproterenol in a $2.5 \%$ glucose solution was infused at a rate of 0.5 $\mathrm{ml} / \mathrm{min}$ either i.v. or into the renal artery. A dose of 0.018 $\mu \mathrm{g} / \mathrm{kg}$ per min was used in all the i.v. experiments except one and in four of the intrarenal experiments. In one of the i.v. and in three of the intrarenal infusions a dose of 0.009 $\mu \mathrm{g} / \mathrm{kg}$ per min was used. An equilibration period of $10-20$ min was allowed to elapse and then three to five collections of urine were made. The isoproterenol infusion was then discontinued and after another 10-20 min equilibration period three to five postinfusion periods were obtained.

The analytical procedures and calculations for clearances of inulin and PAH and excretion of water and electrolyte have been described elsewhere (27). Renal plasma flow was calculated from the clearance and extraction of PAH. Plasma renin activity (PRA) was measured using an immunoassay for angiotensin I (AI) $(28,29)$ and expressed as nanograms $\mathrm{AI}$ formed per milliliter of plasma during a $3 \mathrm{hr}$ incubation. A rate of renin secretion (RSR) was calculated from the renal arteriovenous difference in plasma renin activity and renal plasma flow, and is expressed as PRA units per minute. All results are expressed as means \pm 1 SE. Statistical significance was determined using the Student $t$ test for paired data from the same animal, except when comparing the results between the innervated and denervated kidneys, in which case the unpaired Student $t$ test was used.

${ }^{1}$ Abbreviations used in this paper: AI, angiotensin I; $\mathrm{PAH}, p$-aminohippuric acid; PRA, plasma renin activity; $\mathrm{RSR}$, renin secretion rate.

\section{RESULTS}

Intravenous isoproterenol. The effects of i.v. isoproterenol infusion on systemic and renal hemodynamics, electrolyte excretion, PRA, and RSR are shown in Table $I$. In all experiments, there was a reversible increase in PRA. Mean PRA increased from $14.7 \pm 3.3$ ( $\mathrm{SE}$ ) to $35.7 \pm 5.2 \mathrm{ng} / \mathrm{ml}$ per $3 \mathrm{hr}$ during the infusion $(P<0.001)$ and decreased to $19.4 \pm 3.5 \mathrm{ng} / \mathrm{ml}$ per $3 \mathrm{hr}$ after the infusion was stopped $(P<0.001)$. Reversible increases in RSR occurred in 21 of the 24 kidneys and were of similar magnitude in the innervated and denervated kidneys. In the innervated kidneys, $\mathrm{RSR}$ rose from $1640 \pm 451$ to $5062 \pm 1170 \mathrm{U} / \mathrm{min}$ during the infusion $(P<0.02)$ and decreased to $2132 \pm 425 \mathrm{U} / \mathrm{min}$ after cessation of the infusion $(\mathrm{P}<0.05)$. In the denervated kidneys, the mean $\mathrm{RSR}$ during the preinfusion control period was $455 \pm 142 \mathrm{U} / \mathrm{min}$ and this was significantly lower than the corresponding value in the innervated kidneys $(P<0.02)$. RSR in the denervated kidneys increased to $2762 \pm 546 \mathrm{U} / \mathrm{min}$ during the isoproterenol infusion $(P<0.001)$ and decreased to 935 $\pm 347 \mathrm{U} / \mathrm{min}$ after the infusion was stopped $(P<$ $0.001)$. The postinfusion control value in these kidneys was also significantly lower than the corresponding value in the innervated kidneys $(P<0.05)$.

These changes in renin secretion during i.v. infusion of isoproterenol were associated with large increases in cardiac output and small decreases in systemic arterial pressure. Cardiac output increased from $3.7 \pm 0.2$ to $5.5 \pm 0.4$ liters $/ \mathrm{min}$ during the infusion $(P<0.001)$ and decreased to $3.5 \pm 0.3$ liters $/ \mathrm{min}$ after cessation of the infusion $(P<0.001)$. Systemic arterial pressure decreased from $143 \pm 5$ to $135 \pm 6 \mathrm{~mm} \mathrm{Hg}$ during the infusion $(P<0.05)$ and increased to $141 \pm 4 \mathrm{~mm} \mathrm{Hg}$ after the infusion was stopped $(P<0.02)$.

The decrease in systemic arterial pressure was not transmitted to the kidneys since renal perfusion pressure was maintained at a constant level by adjustment of the aortic clamp. The infusion of isoproterenol was not associated with significant changes in either glomerular filtration rate or renal plasma flow. During preinfusion control periods, sodium excretion by the denervated kidneys was significantly higher than that by innervated kidneys $(P<0.02)$. Sodium excretion did not change during the isoproterenol infusion, but increased slightly in both innervated and denervated kidneys after the infusion was stopped. Potassium excretion did not change in either innervated or denervated kidneys when the isoproterenol was infused, but there was a small increase by the innervated kidneys after cessation of the infusion.

In the animals in which the pituitary was intact, 
TABLE I

Effect of I.v. Isoproterenol on Systemic and Renal

\begin{tabular}{|c|c|c|c|c|c|c|c|c|c|c|c|c|}
\hline \multirow[b]{2}{*}{ Dog* } & \multicolumn{3}{|c|}{ Cardiac output } & \multicolumn{3}{|c|}{ Systemic arterial pressure } & \multicolumn{3}{|c|}{ Renal perfusion pressure } & \multicolumn{3}{|c|}{ Plasma renin activity } \\
\hline & $\begin{array}{l}\text { Pre- } \\
\text { contf }\end{array}$ & Iso & $\begin{array}{l}\text { Post- } \\
\text { contf }\end{array}$ & $\begin{array}{l}\text { Pre- } \\
\text { cont }\end{array}$ & Iso & $\begin{array}{l}\text { Post- } \\
\text { cont }\end{array}$ & $\begin{array}{l}\text { Pre- } \\
\text { cont }\end{array}$ & Iso & $\begin{array}{l}\text { Post- } \\
\text { cont }\end{array}$ & $\begin{array}{l}\text { Pre- } \\
\text { cont }\end{array}$ & Iso & $\begin{array}{l}\text { Post- } \\
\text { cont }\end{array}$ \\
\hline & \multicolumn{3}{|c|}{ liters/min } & \multicolumn{3}{|c|}{$m m \mathrm{Hg}$} & \multicolumn{3}{|c|}{$m m \mathrm{Hg}$} & \multicolumn{3}{|c|}{$n g / m l / 3 \mathrm{hr}$} \\
\hline 1 & 3.7 & 4.2 & 3.1 & 140 & 140 & 140 & 140 & 140 & 140 & 13.1 & 30.0 & 23.5 \\
\hline \multirow[t]{2}{*}{2} & 3.8 & 4.8 & 3.0 & 160 & 150 & 150 & 145 & 147 & 145 & 29.0 & 62.0 & 44.0 \\
\hline & 3.0 & 4.6 & 3.1 & 150 & 143 & 145 & 145 & 143 & 145 & 44.0 & 58.5 & 42.0 \\
\hline \multirow[t]{2}{*}{3} & 4.2 & 6.7 & 4.4 & 155 & 168 & 168 & 132 & 137 & 135 & 11.7 & 20.4 & 17.4 \\
\hline & 4.4 & 5.9 & 4.6 & 168 & 167 & 162 & 135 & 136 & 138 & 17.4 & 35.5 & 22.5 \\
\hline 4 & 5.0 & 6.8 & 4.8 & 112 & 100 & 115 & 103 & 100 & 100 & 11.7 & 40.5 & 17.2 \\
\hline 5 & 3.4 & 4.0 & 2.5 & 145 & 123 & 143 & 122 & 123 & 118 & 10.3 & 30.5 & 8.8 \\
\hline 6 & 3.1 & 4.8 & 2.0 & 125 & 120 & 130 & 110 & 110 & 110 & 12.4 & 68.0 & 17.4 \\
\hline 7 & 2.8 & 6.5 & 3.1 & 155 & 130 & 137 & 130 & 130 & 127 & 7.5 & 20.5 & 10.7 \\
\hline 8 & 5.0 & 8.5 & 5.5 & 160 & 142 & 143 & 135 & 135 & 135 & 5.2 & 17.0 & 12.0 \\
\hline \multirow[t]{2}{*}{9} & 2.9 & 4.8 & 2.9 & 117 & 115 & 128 & 117 & 115 & 110 & 4.1 & 28.3 & 9.6 \\
\hline & 2.9 & 4.5 & 2.5 & 128 & 122 & 132 & 110 & 115 & 118 & 9.6 & 17.0 & 7.3 \\
\hline Mean & 3.7 & 5.5 & 3.5 & 143 & 135 & 141 & 127 & 128 & 127 & 14.7 & 35.7 & 19.4 \\
\hline $\begin{array}{l}\text { SE } \\
P \text { value }\end{array}$ & \pm 0.2 & 01 & \pm 0.3 & \pm & ${ }^{ \pm 6}<$ & ${ }_{2}^{ \pm 4}$ & \pm 4 & \pm 4 & \pm 4 & \pm 3.3 & $\begin{array}{r} \pm 5.2 \\
01\end{array}$ & ${ }_{01}^{ \pm 3.5}$ \\
\hline
\end{tabular}

* Two experiments werè performed in $\operatorname{dogs} 2,3$, and 9 ; dogs $2,4-6$, and 9 were hypophysectomized.

$\ddagger$ Pre-cont, control values before isoproterenol infusion; Iso, values during isoproterenol infusion; Post-cont, values after cessation of infusion.

Denervated kidneys; L, left kidney; R, right kidney.

isoproterenol infusion was associated with a significant antidiuresis. This effect has been described previously and apparently is due to an effect of isoproterenol to stimulate the release of vasopressin (30). This antidiuretic effect did not occur in the hypophysectomized animals. In this latter group of five animals urine flow rates before, during and after the infusion were 3.1 $\pm 0.4,2.6 \pm 0.3$, and $2.9 \pm 0.4 \mathrm{ml} / \mathrm{min}$, respectively. The corresponding values for free water clearance were $2.1 \pm$ $0.3,1.7 \pm 0.3$, and $2.1 \pm 0.3 \mathrm{ml} / \mathrm{min}$, and for urinary osmolality were $91 \pm 7,100 \pm 10$, and $78 \pm 6 \mathrm{mOsm} / \mathrm{kg} \mathrm{H} \mathrm{H}_{2} \mathrm{O}$. None of these changes was statistically significant ex- cept the decrease in urinary osmolality which occurred after cessation of the infusion $(P<0.01)$.

In these experiments involving i.v. infusion of isoproterenol, there were no significant and reversible changes in plasma sodium, potassium, or protein concentration. The hematocrit, however, increased from $42.4 \pm 1.7$ to $45.8 \pm 1.3 \%$ during the infusion $(P<0.001)$ and decreased to $42.5 \pm 1.5 \%$ after the infusion was stopped $(P<0.001)$.

Intrarenal isoproterenol. The effects of renal arterial infusion of isoproterenol on systemic and renal hemodynamics, electrolyte excretion and renin secretion are 
Hemodynamics, Electrolyte Excretion, and Renin Secretion

\begin{tabular}{|c|c|c|c|c|c|c|c|c|c|c|c|c|c|c|c|}
\hline & \multicolumn{3}{|c|}{ Renin secretion rate } & \multicolumn{3}{|c|}{ Glomerular filtration rate } & \multicolumn{3}{|c|}{ Renal plasma flow } & \multicolumn{3}{|c|}{ Sodium excretion } & \multicolumn{3}{|c|}{ Potassium excretion } \\
\hline & $\begin{array}{l}\text { Pre- } \\
\text { cont }\end{array}$ & Iso & $\begin{array}{l}\text { Post- } \\
\text { cont }\end{array}$ & $\begin{array}{l}\text { Pre- } \\
\text { cont }\end{array}$ & Iso & $\begin{array}{l}\text { Post- } \\
\text { cont }\end{array}$ & $\begin{array}{l}\text { Pre- } \\
\text { cont }\end{array}$ & Iso & $\begin{array}{l}\text { Post- } \\
\text { cont }\end{array}$ & $\begin{array}{l}\text { Pre- } \\
\text { cont }\end{array}$ & Iso & $\begin{array}{l}\text { Post- } \\
\text { cont }\end{array}$ & $\begin{array}{l}\text { Pre- } \\
\text { cont }\end{array}$ & Iso & $\begin{array}{r}\text { Post- } \\
\text { cont }\end{array}$ \\
\hline & \multicolumn{3}{|c|}{$U / \min$} & \multicolumn{3}{|c|}{$m l / m i n$} & \multicolumn{3}{|c|}{$m l / m i n$} & \multicolumn{3}{|c|}{$\mu E q / \min$} & \multicolumn{3}{|c|}{$\mu E q / \min$} \\
\hline L & 3080 & 2244 & 513 & 56.2 & 60.0 & 65.7 & 200 & 187 & 205 & 12.5 & 11.9 & 33.2 & 34 & 33 & 44 \\
\hline $\mathbf{R}$ & 2245 & 3456 & 2024 & 51.1 & 56.5 & 60.9 & 206 & 192 & 213 & 5.0 & 4.6 & 11.5 & 25 & 26 & 34 \\
\hline $\mathbf{L}$ & 0 & 2772 & 1925 & 45.9 & 45.2 & 47.5 & 154 & 132 & 154 & 7.5 & 5.1 & 8.1 & 19 & 16 & 24 \\
\hline $\mathbf{R}$ & 2048 & 3360 & 3308 & 47.1 & 51.3 & 54.3 & 195 & 160 & 189 & 7.5 & 7.4 & 9.8 & 23 & 16 & 26 \\
\hline $\mathbf{L}$ & 1925 & 5360 & 824 & 47.5 & 51.7 & 56.2 & 154 & 160 & 206 & 8.1 & 7.0 & 13.2 & 24 & 23 & 32 \\
\hline $\mathbf{R}$ & 3308 & 5425 & 1892 & 54.3 & 52.8 & 55.6 & 189 & 155 & 172 & 9.8 & 12.0 & 17.7 & 26 & 24 & 33 \\
\hline L\& & 354 & 2152 & 1363 & 60.1 & 72.4 & 66.2 & 161 & 203 & 213 & 7.7 & 32.3 & 30.4 & 35 & 75 & 69 \\
\hline $\mathrm{R}$ & 2258 & 4155 & 4799 & 57.2 & 66.5 & 71.4 & 166 & 212 & 258 & 9.0 & 25.4 & 23.4 & 35 & 64 & 65 \\
\hline L\& & 1363 & 3105 & 0 & 66.2 & 68.6 & 82.0 & 213 & 207 & 269 & 30.4 & 49.5 & 69.0 & 69 & 99 & 108 \\
\hline $\mathrm{R}$ & 4799 & 8748 & 3878 & 71.4 & 67.1 & 80.6 & 258 & 216 & 277 & 23.4 & 28.7 & 36.2 & 65 & 76 & 88 \\
\hline L\& & 1023 & 7053 & 3741 & 50.4 & 51.2 & 51.5 & 155 & 155 & 145 & 1.3 & 0.5 & 1.1 & 28 & 22 & 24 \\
\hline $\mathbf{R}$ & 988 & 15240 & 2599 & 38.5 & 36.5 & 38.6 & 122 & 120 & 122 & 5.4 & 4.6 & 5.0 & 21 & 14 & 16 \\
\hline L\& & -319 & -125 & 388 & 38.4 & 37.5 & 34.2 & 152 & 125 & 97 & 4.9 & 1.6 & 3.1 & 17 & 12 & 12 \\
\hline $\mathbf{R}$ & 434 & 1785 & 1250 & 30.9 & 34.9 & 26.2 & 140 & 119 & 71 & 0.5 & 0.6 & 0.6 & 14 & 11 & 8 \\
\hline L & 644 & 5252 & 442 & 30.3 & 31.3 & 23.6 & 113 & 101 & 69 & 4.1 & 0.7 & 0 & 12 & 12 & 6 \\
\hline$R \S$ & 888 & 3430 & 576 & 28.0 & 28.1 & 17.7 & 111 & 98 & 57 & 1.8 & 0.7 & 0.2 & 13 & 11 & 6 \\
\hline $\mathrm{L} \S$ & 93 & 2485 & 393 & 39.9 & 39.7 & 47.9 & 133 & 142 & 157 & 102 & 98 & 125 & 25 & 27 & 31 \\
\hline $\mathrm{R} \S$ & 142 & 4278 & 227 & 40.0 & 41.4 & 44.3 & 129 & 145 & 142 & 59 & 51 & 57 & 24 & 25 & 30 \\
\hline L\& & 540 & 2838 & 1342 & 66.4 & 73.2 & 69.8 & 216 & 227 & 244 & 48.7 & 20.2 & 36.3 & 43 & 33 & 43 \\
\hline $\mathrm{R} \S$ & 1189 & 5473 & 3416 & 65.2 & 64.0 & 69.2 & 205 & 199 & 244 & 53.7 & 22.4 & 41.6 & 41 & 34 & 41 \\
\hline $\mathrm{L} \S$ & 133 & 1950 & 384 & 26.1 & 24.8 & 24.5 & 95 & 99 & 80 & 12 & 11.6 & 10.2 & 19 & 17 & 16 \\
\hline $\mathrm{R} \S$ & 38 & 986 & 83 & 24.4 & 23.6 & 23.1 & 94 & 88 & 69 & 42 & 5.9 & 6.3 & 18 & 17 & 15 \\
\hline L\& & 384 & 1120 & 86 & 24.5 & 25.9 & 25.8 & 80 & 80 & 78 & 10.2 & 14.3 & 22.4 & 16 & 19 & 19 \\
\hline \multirow[t]{4}{*}{$R \&$} & 83 & 1155 & 156 & 23.1 & 24.6 & 24.6 & 69 & 70 & 71 & 6.3 & 11.5 & 20.7 & 15 & 18 & 17 \\
\hline & 1640 & 5062 & 2132 & 48.2 & 50.3 & 52.8 & 172 & 159 & 176 & 8.4 & 9.8 & 14.4 & 27 & 29 & 34 \\
\hline & \pm 451 & \pm 1170 & \pm 425 & \pm 3.6 & \pm 3.7 & \pm 5.4 & \pm 13 & \pm 12 & \pm 20 & \pm 1.8 & \pm 2.8 & \pm 3.7 & \pm 4 & \pm 7 & \pm 7 \\
\hline & \multicolumn{3}{|c|}{$<0.02<0.05$} & \multicolumn{2}{|c|}{ NS } & NS & \multicolumn{3}{|c|}{ NS NS } & \multicolumn{3}{|c|}{ NS $<0.05$} & \multicolumn{3}{|c|}{ NS $<0.02$} \\
\hline Mean§ & 455 & 2762 & 935 & 42.5 & 44.2 & 44.7 & 139 & 141 & 144 & 29.2 & 24.6 & 32.6 & 28 & 31 & 33 \\
\hline SE\& & \pm 142 & \pm 546 & \pm 347 & \pm 4.8 & \pm 5.4 & \pm 6.0 & \pm 14 & \pm 15 & \pm 21 & \pm 8.4 & \pm 7.7 & \pm 9.8 & \pm 4 & \pm 7 & \pm 8 \\
\hline$P$ value $\S$ & \multicolumn{3}{|c|}{$<0.001<0.001$} & \multicolumn{3}{|c|}{ NS N } & \multicolumn{3}{|c|}{ NS NS } & \multicolumn{3}{|c|}{$\mathrm{NS} \quad<0.02$} & \multicolumn{3}{|c|}{ NS NS } \\
\hline
\end{tabular}

shown in Table II. There were no significant changes in cardiac output or blood pressure and renal hemodynamics and electrolyte excretion did not change significantly in either the ipsilateral or contralateral kidneys. There was not a statistically significant increase in RSR in either the ipsilateral or contralateral kidneys. A small but significant increase in PRA did occur during the isoproterenol infusion, but no significant decrease in PRA occurred when the infusion was stopped. There were no significant changes in plasma sodium, potassium, protein concentration, or arterial hematocrit.

\section{DISCUSSION}

The present results are in agreement with previous reports that beta adrenergic stimulation increases the release of renin $(8,25,26)$. The main purpose of the present experimental design was to determine if this effect of beta adrenergic stimulation is attributable to a direct response of intrarenal beta adrenergic receptors or whether some systemic effect of beta adrenergic stimulation initiates extrarenal events that lead to increased release of renin. The amount of isoproterenol infused into the renal artery in these studies exposed 
TABLE II

The Effect of Renal Arterial Infusion of Isoproterenol on Systemic

\begin{tabular}{|c|c|c|c|c|c|c|c|c|c|c|c|c|c|}
\hline \multirow[b]{2}{*}{ Dog* } & \multicolumn{3}{|c|}{ Cardiac output } & \multicolumn{3}{|c|}{ Arterial blood pressure } & \multicolumn{3}{|c|}{ Plasma renin activity } & & \multicolumn{3}{|c|}{ Renin secretion rate } \\
\hline & $\begin{array}{l}\text { Pre- } \\
\text { cont }\end{array}$ & Iso & $\begin{array}{l}\text { Post- } \\
\text { cont }\end{array}$ & $\begin{array}{l}\text { Pre- } \\
\text { cont }\end{array}$ & Iso & $\begin{array}{l}\text { Post- } \\
\text { cont }\end{array}$ & $\begin{array}{l}\text { Pre- } \\
\text { cont }\end{array}$ & Iso & $\begin{array}{l}\text { Post- } \\
\text { cont }\end{array}$ & & $\begin{array}{l}\text { Pre- } \\
\text { cont }\end{array}$ & Iso & $\begin{array}{l}\text { Post- } \\
\text { cont }\end{array}$ \\
\hline & \multicolumn{3}{|c|}{ liters/min } & \multicolumn{3}{|c|}{$m m \mathrm{Hg}$} & \multicolumn{3}{|c|}{$n g / m l / 3 h r$} & & \multicolumn{3}{|c|}{$U / \min$} \\
\hline 10 & 4.4 & 4.3 & 3.9 & 162 & 151 & 152 & 4.3 & 6.3 & 3.3 & I & 235 & 414 & 144 \\
\hline \multirow{2}{*}{11} & 5.2 & 4.8 & 4.5 & 147 & 150 & 153 & 3.8 & 8.0 & 4.8 & I & $\begin{array}{l}524 \\
824\end{array}$ & $\begin{array}{r}400 \\
3050\end{array}$ & $\begin{array}{r}100 \\
1019\end{array}$ \\
\hline & 0.2 & & 1.0 & & & & & & & C & 955 & 2203 & 1430 \\
\hline \multirow[t]{4}{*}{12} & 5.6 & 4.8 & 4.8 & 157 & 133 & 126 & 7.3 & 15.0 & 24.5 & I & 601 & 3864 & 3818 \\
\hline & & & & & & & & & & $\mathrm{C}$ & 1416 & 3750 & 5365 \\
\hline & 4.8 & 4.8 & 4.8 & 126 & 125 & 115 & 24.5 & 26.0 & 24.5 & I & 3818 & 2925 & 2430 \\
\hline & & & & & & & & & & C & 5365 & 3240 & 3828 \\
\hline \multirow[t]{4}{*}{13} & - & - & - & 137 & 135 & 135 & 1.8 & 5.4 & 4.1 & I & 851 & 785 & 350 \\
\hline & & & & & & & & & & C & 710 & 268 & 409 \\
\hline & - & - & - & 135 & 138 & 100 & 4.1 & 6.5 & 7.0 & I & 350 & 426 & 403 \\
\hline & & & & & & & & & & $\mathrm{C}$ & 409 & 474 & 1241 \\
\hline \multirow[t]{3}{*}{14} & 3.5 & 3.5 & 3.0 & 114 & 110 & 97 & 59.0 & 57.5 & 53.0 & I & -380 & 1032 & 2648 \\
\hline & & & & & & & & & & C & 1521 & 495 & 1314 \\
\hline & & & & & & & & & & Ipsilateral & & & \\
\hline \multirow{6}{*}{$\begin{array}{l}\text { Mean } \\
\text { SE } \\
P \text { value }\end{array}$} & 4.7 & 4.4 & 4.2 & 140 & 135 & 125 & 15.0 & 17.8 & 17.3 & & 900 & 1785 & 1545 \\
\hline & \pm 0.4 & \pm 0.3 & \pm 0.3 & \pm 6 & \pm 5 & \pm 9 & \pm 7.9 & \pm 7.2 & \pm 6.9 & & \pm 512 & \pm 546 & \pm 538 \\
\hline & & & & & $S \quad 1$ & & & 05 & & & & & \\
\hline & & & & & & & & & & Contralateral & & & \\
\hline & & & & & & & & & & $\begin{array}{l}\text { Mean } \\
\mathrm{SE}\end{array}$ & $\begin{array}{r}1529 \\
\pm 663\end{array}$ & $\begin{array}{r}1559 \\
\pm 560\end{array}$ & $\begin{array}{r}1964 \\
\pm 723\end{array}$ \\
\hline & & & & & & & & & & $P$ value & & & \\
\hline
\end{tabular}

I, values in ipsilateral kidney receiving renal arterial infusion; $C$, values in the noninfused contralateral kidney. Other abbreviations as in Table I.

* Two experiments were performed in dogs 12 and 13. Dog 14 was hypophysectomized, both kidneys were denervated, and phenoxybenzamine $(0.1 \mu \mathrm{g} / \mathrm{kg}$ per $\mathrm{min})$ was infused into the ipsilateral kidney throughout the experiment.

the kidney to even more of the agent than would have reached the kidney during the i.v. infusion of isoproterenol. Nevertheless, an increased secretion of renin occurred only when the agent was infused i.v.

It might be expected that the infusion of isoproterenol into the renal artery would result in the delivery of the agent into the general circulation in an amount sufficient to produce extrarenal effects similar to those occurring when the agent was infused i.v. The failure to observe changes in systemic hemodynamics during the renal arterial infusion of isoproterenol suggested that the kidney was removing or otherwise inactivating much of the agent. Recent studies in our laboratory support this conclusion by showing that when labeled isoproterenol is infused into the renal artery less than $50 \%$ appears in the renal vein. ${ }^{2}$ This efficient removal of isoproterenol by the kidney permits an ex-

${ }^{2}$ Lifschitz, M., A. Goldfein, and R. W. Schrier. Unpublished data. perimental design for examining the intrarenal effects of relatively large doses of isoproterenol without altering systemic hemdynamics.

Since the i.v. but not the renal arterial infusion of isoproterenol increased renin secretion we conclude that beta adrenergic stimulation with isoproterenol increased release of renin by an extrarenal effect of the agent. This conclusion is at variance with prior suggestions that isoproterenol stimulates the release of renin as a result of a direct action on intrarenal beta adrenergic receptors (21). Some of the evidence for the existence of intrarenal beta adrenergic receptors which control renin release is derived from previous demonstrations that the renal arterial infusion of isoproterenol increased plasma renin activity $(8,25,26)$. However, other investigators have not observed an effect of renal arterial infusion of isoproterenol on renin release (2). In addition, the doses of the drug used in all of these earlier experiments were larger than those used in the present study and, thus, any effect 
and Renal Hemodynamics, Electrolyte Excretion, and Renin Secretion

\begin{tabular}{|c|c|c|c|c|c|c|c|c|c|c|c|}
\hline \multicolumn{3}{|c|}{ Glomerular filtration rate } & \multicolumn{3}{|c|}{ Renal plasma flow } & \multicolumn{3}{|c|}{ Sodium excretion } & \multicolumn{3}{|c|}{ Potassium excretion } \\
\hline $\begin{array}{l}\text { Pre- } \\
\text { cont }\end{array}$ & Iso & $\begin{array}{l}\text { Post- } \\
\text { cont }\end{array}$ & $\begin{array}{l}\text { Pre- } \\
\text { cont }\end{array}$ & Iso & $\begin{array}{c}\text { Post- } \\
\text { cont }\end{array}$ & $\begin{array}{l}\text { Pre- } \\
\text { cont }\end{array}$ & Iso & $\begin{array}{l}\text { Post- } \\
\text { cont }\end{array}$ & $\begin{array}{l}\text { Pre- } \\
\text { cont }\end{array}$ & Iso & $\begin{array}{l}\text { Post- } \\
\text { cont }\end{array}$ \\
\hline \multicolumn{3}{|c|}{$m l / \min$} & \multicolumn{3}{|c|}{$m l / m i n$} & \multicolumn{3}{|c|}{$\mu E q / \min$} & \multicolumn{3}{|c|}{$\mu E q / \min$} \\
\hline 52.0 & 51.4 & 52.1 & 235 & 207 & 206 & 28.9 & 40.2 & 46.9 & 18 & 21 & 20 \\
\hline 49.3 & 47.4 & 48.3 & 249 & 200 & 229 & 19.0 & 22.3 & 32.2 & 17 & 17 & 19 \\
\hline 62.9 & 63.8 & 72.7 & 317 & 391 & 392 & 19.2 & 20.7 & 23.4 & 51 & 58 & 74 \\
\hline 67.8 & 63.1 & 61.9 & 308 & 272 & 275 & 7.4 & 7.8 & 9.7 & 49 & 46 & 54 \\
\hline 50.5 & 48.2 & 49.6 & 167 & 161 & 166 & 34.9 & 43.2 & 46.8 & 29 & 30 & 29 \\
\hline 47.9 & 42.8 & 45.5 & 149 & 150 & 185 & 30.8 & 35.3 & 44.9 & 26 & 25 & 26 \\
\hline 49.6 & 56.9 & 43.5 & 166 & 195 & 108 & 46.8 & 60.9 & 45.7 & 29 & 31 & 31 \\
\hline 45.5 & 52.0 & 41.4 & 185 & 209 & 116 & 44.9 & 52.7 & 48.4 & 26 & 28 & 29 \\
\hline 46.0 & 40.8 & 37.5 & 152 & 157 & 106 & 38.5 & 16.6 & 10.0 & 26 & 19 & 23 \\
\hline 45.1 & 42.8 & 39.9 & 222 & 206 & 186 & 51.8 & 47.1 & 43.7 & 37 & 21 & 11 \\
\hline 37.5 & 43.3 & 39.3 & 106 & 129 & 144 & 10.0 & 13.5 & 8.9 & 23 & 27 & 22 \\
\hline 39.9 & 39.8 & 34.1 & 186 & 206 & 197 & 43.7 & 43.1 & 36.8 & 11 & 7 & 4 \\
\hline 39.2 & 38.1 & 31.8 & 190 & 172 & 141 & 18.1 & 27.8 & 13.9 & 35 & 31 & 23 \\
\hline 36.1 & 35.1 & 31.8 & 169 & 165 & 146 & 10.8 & 20.0 & 13.7 & 28 & 28 & 24 \\
\hline 48.2 & 48.9 & 46.6 & 190 & 202 & 180 & 28.1 & 31.8 & 27.9 & 30 & 31 & 32 \\
\hline \multirow[t]{2}{*}{ \pm 3.2} & \pm 3.5 & \pm 5.1 & \pm 26 & \pm 33 & \pm 38 & \pm 4.9 & \pm 6.5 & \pm 6.8 & \pm 4 & \pm 5 & \pm 7 \\
\hline & \multicolumn{2}{|c|}{ NS } & \multicolumn{2}{|c|}{ NS } & & \multicolumn{2}{|c|}{ NS } & & \multicolumn{2}{|c|}{ NS } & NS \\
\hline 47.4 & 46.1 & 43.3 & 210 & 201 & 191 & 29.8 & 32.6 & 32.8 & 28 & 25 & 24 \\
\hline \multirow[t]{2}{*}{ \pm 3.8} & \pm 3.5 & \pm 3.8 & \pm 21 & \pm 15 & \pm 20 & \pm 6.7 & \pm 6.2 & \pm 5.8 & \pm 5 & \pm 5 & \pm 6 \\
\hline & \multicolumn{2}{|c|}{ NS } & \multicolumn{2}{|c|}{ NS } & & \multicolumn{2}{|c|}{ NS } & & \multicolumn{2}{|c|}{ NS } & NS \\
\hline
\end{tabular}

on renin secretion could have been initiated by extrarenal actions of the drug. This possibility cannot be evaluated since cardiac output and total peripheral resistance were not measured in these previous studies $(2,8,25,26)$. Measurements of arterial pressure alone may not be adequate to exclude a systemic effect of isoproterenol since in the present study cardiac output often increased, with little or no change in arterial pressure, indicating a large fall in peripheral resistance. Moreover, in other studies the effect of infusing isoproterenol into a renal artery was not compared with the effect in the contralateral noninfused kidney $(2,8,25,26)$-a comparison that would seem necessary in order to document an intrarenal effect on the release of renin. In one previous study the effect of the renal arterial infusion of isoproterenol on renin release has been compared with the effect of an i.v. infusion of the drug (25). Although the renal arterial infusion was associated with a larger effect on renin release, two aspects of the study make this finding dif- ficult to interpret. Specifically, the study was performed in animals with hypertension secondary to constriction of a renal artery and isoproterenol was infused into the constricted renal artery. Moreover, the renal arterial infusion was begun after an hour of i.v. infusion of the drug, and there were no studies to examine whether a $2 \mathrm{nd} \mathrm{hr}$ of i.v. infusion of isoproterenol would have similarly increased the release of renin.

The finding that large doses of the beta adrenergic blocking agent, propranolol, may abolish or attenuate the effect of several maneuvers which otherwise increase renin secretion $(7,11,14)$ does not necessarily provide evidence for the existence of an intrarenal beta adrenergic receptor controlling renin release. In such studies, propranolol has been administered systemically and, thus, selective intrarenal beta adrenergic blockade has not been achieved. Therefore, the action of propranolol to abolish the effects of adrenergic discharge on renin secretion could be a consequence of either extrarenal or intrarenal beta adrenergic block- 
ade. However, the finding that propranolol abolishes the increased release of renin after stimulation of the renal nerves suggests an intrarenal role of beta adrenergic receptors. It is possible that properties of propranolol other than its effect to block beta adrenergic receptors may be involved in this altered response to stimulation of renal nerves. For instance, propranolol may prevent effects of renal nerve stimulation to increase renal vascular tone or to decrease the excretion of sodium, changes which should influence the release of renin. In this regard, it has been reported that both the $d$ - and $l$-isomers of propranolol block the effect of norepinephrine to increase renin release (31) even though only the $l$-isomer possesses beta adrenergic blocking properties (32).

In the present study, several stimuli which are known to increase the release of renin can be excluded as mediating the observed response to i.v. isoproterenol. Although arterial pressure usually decreased during the i.v. infusion of isoproterenol, this change was not transmitted to the kidneys since the experimental design permitted the maintenance of unchanged renal perfusion pressure. Thus, the increased release of renin which occurred during the i.v. infusion of isoproterenol could not have been due to an effect of mean renal perfusion pressure on an intrarenal baroreceptor.

There is evidence that the release of renin may be influenced by the amount of sodium delivered to, or transported at, the macula densa, independently of an effect on renal perfusion pressure $(17,18)$. In the present studies there was no evidence that the delivery of filtrate to the macula densa decreased during the i.v. infusion of isoproterenol. Neither glomerular filtration rate nor sodium excretion diminished during the i.v. infusion of isoproterenol, changes which may be associated with a diminution in delivery of filtrate to distal tubular sites. Moreover, during water diuresis in the hypophysectomized animals, urinary volume and free water clearance did not decrease. This provides additional evidence that the delivery of filtrate from the proximal tubule and reabsorption of sodium by the distal tubule were unchanged, as the release of renin increased during the i.v. infusion of isoproterenol.

The present results also demonstrate that the effect of i.v. infusion of isoproterenol to increase renin secretion is not dependent on renal innervation. Although renal denervation reduced the control rate of renin secretion, it did not significantly alter the effect of i.v. isoproterenol to stimulate renin release.

It seems possible that the effect of i.v. isoproterenol to increase the secretion of renin was related to the systemic hemodynamic consequences of extrarenal beta adrenergic stimulation. I.v. isoproterenol resulted in increased cardiac output and decreased peripheral re- sistance but neither of these hemodynamic changes occurred during the renal arterial infusion of isoproterenol which also failed to increase the release of renin. A similar extrarenal hemodynamic pathway has been proposed for the antidiuretic effect of beta adrenergic stimulation, since antidiuresis (and systemic hemodynamic changes) also occurs with i.v. but not renal arterial infusion of isoproterenol (30). Vasopressin appears to be the mediator of this antidiuretic effect of i.v. isoproterenol since the effect is abolished by hypophysectomy. Vasopressin does not seem to be the mediator of the effect of i.v. isoproterenol to stimulate renin secretion, since the effect on renin was not altered by hypophysectomy. However, since the increase in renin secretion occurred in the absence of a change in renal perfusion pressure, glomerular filtration rate, renal plasma flow, and electrolyte excretion, and was not abolished by renal denervation, the possibility exists that the effect of systemic beta adrenergic stimulation is mediated by a change in the level of some circulatory substance other than vasopressin. The only compositional change in blood that was measured during i.v. isoproterenol was a small increase in hematocrit. Although an effect of hematocrit on renin secretion has not been described, we have previously demonstrated that large changes in hematocrit may alter renal hemodynamics and sodium excretion (27). Even so, the small changes in hematocrit observed in the present study were not associated with changes in either renal hemodynamics or sodium excretion.

It seems possible that the fall in systemic arterial pressure that frequently accompanied i.v. infusion of isoproterenol could result secondarily in increased activity of the sympathetic nervous system. If so, an increase in the circulating level of catecholamines could be involved in mediating the increased release of renin. Some evidence consistent with increased adrenergic discharge during the i.v. infusion of isoproterenol was the increase in hematocrit, which may have been caused by a release of red blood cells from the spleen. It would appear, however, on the basis of the present results, that any effect of adrenergic discharge and circulating catecholamines on renin release would not be mediated through intrarenal beta adrenergic receptors. Alternatively, if a change in the plasma concentration of catecholamines is not involved, then some other undefined circulatory factor may mediate the effect of i.v. isoproterenol to increase the secretion of renin.

\section{ACKNOWLEDGMENTS}

The authors wish to express their gratitude to Dr. W. F. Ganong for his helpful suggestions, to Judith Harbottle, Lisbeth Streiff, Helen Hughes, and Roy Shackelford for 
technical assistance and to Dana Tully-Smith and Vicki Wagner for their secretarial assistance.

These studies were supported by Grants AM 06704, AM 12753, and HE 13319-01A1 from the National Institutes of Health; Grant NGR 05025007 from the National Aeronautics and Space Administration; and the L. J. and Mary C. Skaggs Foundation.

\section{REFERENCES}

1. Huidobro, F., and E. Braun-Menéndez. 1942. Secretion of renin by the intact kidney. Amer. J. Physiol. 137: 47.

2. Bunag, R. D., I. H. Page, and J. W. McCubbin. 1966. Neural stimulation of release of renin. Circ. Res. 19: 851.

3. Blaine, E. H., J. O. Davis, and R. T. Witty. 1970. Renin release after hemorrhage and after suprarenal aortic constriction in dogs without sodium delivery to the macula densa. Circ. Res. 27: 1081.

4. Blaine, E. H., and J. O. Davis. 1971. Evidence for a renal vascular mechanism in renin release: new observations with graded stimulation by aortic constriction. Circ. Res. 28, 29(Suppl. II) : II-118.

5. Vander, A. J. 1965. Effect of catecholamines and the renal nerves on renin secretion in anesthetized dogs. Amer. J. Physiol. 209 : 659.

6. Ganong, W. F. 1972. Sympathetic effects on renin secretion: mechanism and physiological role. In Control of Renin Secretion. T. Assaykeen, editor. Plenum Press, New York. 17.

7. Ganong, W. F. 1972. Effects of sympathetic activity and ACTH on renin and aldosterone secretion. In Proceedings of the International Symposium on the Renin-Angiotensin-Aldosterone-Sodium System in $\mathrm{Hy}$ pertension. J. Genest, editor. Springer-Verlag KG, Berlin. In press.

8. Ueda, H., H. Yasuda, Y. Takabatake, M. Iizuka, T. Iizuka, M. Ihori, and Y. Sakamoto. 1970. Observations on the mechanism of renin release by catecholamines. Circ. Res. 26, 27 (Suppl. II) : II-195.

9. Wathen, R. L., W. S. Kingbury, D. A. Stouder, E. G. Schneider, and H. H. Rostorfer. 1965. Effects of infusion of catecholamines and angiotensin II on renin release in anesthetized dogs. Amer. J. Physiol. 209: 1012.

10. Otsuka, K., T. A. Assaykeen, A. Goldfien, and W. F. Ganong. 1970. Effect of hypoglycemia on plasma renin activity in dogs. Endocrinology. 87: 1306.

11. Assaykeen, T. A., P. L. Clayton, A. Goldfien, and W. F. Ganong. 1970. Effect of alpha- and beta-adrenergic blocking agents on the renin response to hypoglycemia and epinephrine in dogs. Endocrinology. 87: 1318.

12. Ueda, H., H. Yasuda, Y. Takabatake, M. Iizuka, T. Iizuka, M. Ihori, M. Yamamoto, and Y. Sakamoto. 1967. Increased renin release evoked by mesencephalic stimulation in the dog. Jap. Heart J. 8: 498.

13. Passo, S. S., T. A. Assaykeen, K. Otsuka, B. L. Wise, A. Goldfien, and W. F. Ganong. 1970. Effect of stimulation of the medulla oblongata on renin secretion in dogs. Neuroendocrinology. $7: 1$.

14. Passo, S. S., T. A. Assaykeen, A. Goldfien, and W. F. Ganong. 1970. Effect of alpha- and beta-adrenergic blocking agents on the increase in renin secretion produced by stimulation of the medulla oblongata in dogs. Neuroendocrinology. $7: 97$.
15. Tobian, L., A. Tomboulian, and J. Janecek. 1959. Effect of high perfusion pressure on the granulation of juxtaglomerular cells in an isolated kidney. J. Clin. Invest. 38 : 605.

16. Skinner, S. L., J. W. McCubbin, and I. H. Page. 1963. Renal baroreceptor control of renin secretion. Science (Washington). $141: 814$.

17. Vander, A. J., and R. Miller. 1964. Control of renin secretion in the anesthetized dog. Amer. J. Physiol. 207 : 537.

18. Thurau, K., J. Schnermann, W. Nagel, M. Horster, and M. Wah1. 1967. Composition of tubular fluid in the macula densa segment as a factor, regulating the function of juxtaglomerular apparatus. Circ. Res. 20, 21 : (Suppl. II) : II-79.

19. Martin, D. M., and F. N. White. 1971. Evidence for direct neural release of renin. Fed. Proc. 30: 431. (Abstr.)

20. Johnson, J. A., J. O. Davis, and R. T. Witty. 1971. Control of renin secretion by the renal sympathetic nerves. Physiologist. 14: 168. (Abstr.)

21. Assaykeen, T. A., and W. F. Ganong. 1971. The sympathetic nervous system and renin secretion. In Frontiers in Neuroendocrinology. L. Martini and W. F. Ganong, editors. Oxford University Press, New York. 67.

22. Barajas, J. 1964. Innervation of the juxtaglomerular apparatus. An electron microscopic study of the innervation of the glomerular arterioles. Lab. Invest. 13: 916.

23. Wagermark, J., U. Ungerstedt, and A. Ljungquist. 1968. Sympathetic innervation of the juxtaglomerular cells of the kidney. Circ. Res. 22: 149.

24. Michelakis, A. M., J. Caudle, and G. W. Liddle. 1969. In vitro stimulation of renin production by epinephrine, nor-epinephrine and cyclic AMP. Proc. Soc. Exp. Biol. Med. $130: 748$.

25. Ayers, C. R., R. H. Harris, Jr., and L. G. Lefer. 1969. Control of renin release in experimental hypertension. Circ. Res. 24 (Suppl. I) : I-103.

26. Allison, D. J., P. L. Clayton, S. S. Passo, and T. A. Assaykeen. 1970. The effect of isoproterenol and adrenergic blocking agents on plasma renin activity and renal function in anesthetized dogs. Fed. Proc. 29: 782. (Abstr.)

27. Schrier, R. W., and L. E. Earley. 1970. Effects of hematocrit on renal hemodynamics and sodium excretion in hydropenic and volume-expanded dogs. J. Clin. Invest. $49: 1656$.

28. Stockigt, J. R., R. D. Collins, and E. G. Biglieri. 1971. Determination of plasma renin concentration by angiotensin I immunoassay. Circ. Res. 28, 29 (Suppl. II) : II-175.

29. Reid, I. A., J. R. Stockigt, A. Goldfien, and W. F. Ganong. 1972. Stimulation of renin secretion in dogs by theophylline. Eur. J. Pharmacol. 17: 325.

30. Schrier, R. W., R. Lieberman, and R. C. Ufferman. 1972. Mechanism of antidiuretic effect of beta-adrenergic stimulation. J. Clin. Invest. 51 : 97.

31. Winer, N., D. S. Chokshi, and W. G. Walkenhorst. 1969. Site of action of adrenergic blocking agents on renin secretion. J. Lab. Clin. Med. 74: 1024.

32. Dollery, C. T., J. W. Paterson, and M. E. Conolly. 1969. Clinical pharmacology of $\beta$-receptor blocking drugs. Clin. Pharmacol. Ther. 10: 765. 